Canadian

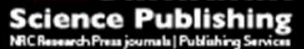

Canadian Journal of Civil Engineering Revue canadienne de génie civil

\title{
Estimate of void fraction and air entrainment flux in hydraulic jump using Froude number
}

\begin{tabular}{|r|l|}
\hline Journal: & Canadian Journal of Civil Engineering \\
\hline Manuscript ID & cjce-2016-0279.R1 \\
\hline Manuscript Type: & Article \\
\hline Date Submitted by the Author: & 02-Jan-2017 \\
\hline $\begin{array}{r}\text { Complete List of Authors: } \\
\text { Is the invited manuscript for } \\
\text { consideration in a Special } \\
\text { Issue? : }\end{array}$ & \\
\hline Chang, Hang; The University of Queensland, School of Civil Engineering \\
\hline Keyword: & $\begin{array}{l}\text { hydraulic structures (HS) < Construction, fluid mech \& hydrodyn < }< \\
\text { Hydrotechnical Eng., environ fluid mechanics < Engineering Mechanics, } \\
\text { water supply-irrig;drain < Hydrotechnical Eng. }\end{array}$ \\
\hline
\end{tabular}

SCHOLARONE ${ }^{\text {m }}$

Manuscripts 


\title{
Estimate of void fraction and air entrainment flux in hydraulic jump using
}

\section{Froude number}

\author{
H. Wang ${ }^{1}$ and H. Chanson ${ }^{1}$ \\ ${ }^{1}$ The University of Queensland, School of Civil Engineering, Brisbane QLD 4072, Australia \\ Corresponding author: H. Wang \\ E-mail: hang.wang@uqconnect.edu.au
}

Word count: 5,423 words 
Abstract: Hydraulic jumps are induced in hydraulic facilities for the purposes of energy dissipation or flow aeration. Presently there is no means for a simple estimate of void fraction distribution and air entrainment flux, without detailed physical modelling. This paper presents a semi-theoretical model to simulate the void fraction and velocity distributions in hydraulic jumps characterised by partially-developed inflow conditions. Relationships were established between the inflow Froude number, jump roller length and key parameters that determine the full expression of void fraction and velocity profiles. The proposed model enables accurate prediction of void fraction, longitudinal velocity and air flux using the inflow Froude number. The results indicated considerable air flux contribution of free-surface aeration, in addition to the singular air entrainment at the jump toe, for moderate to large Froude numbers. A Froude number between 8 and 9 tended to achieve highest aeration rate with maximum total air flux in the roller.

Keywords: hydraulic jumps, void fraction, interfacial velocity, air entrainment flux, selfsimilarity, Froude number

Résumé: Dans les ouvrage hydrauliques, on utlise un ressaut hydraulique pour la dissipation d'energie et l'aeration de l'ecoulement. Actuellement, il n'existe pas de methode simple et precise pour predire les distributions de taux de vide et la quantite d'air entrainee, sans recourir a le la modelisation physique. On presente, ici, une methode semi-theorique pour modeliser les distributons de taux de vide et de vitesses interfaciales, qui permettent de calculer la quantite d'air entrainee en fonction du nombre de Froude. On développe une série d'équations pour les distributions de taux de vide, vitesse et flux d'air, en fonction du nombre de Froude et de certains paramètres clés. Les resultats montrent une contribution importante de l'entrainement d'air a la surface livre, en plus de l'entrappement d'air au coin du ressaut. De 
plus, les resultats suggerent qu'un ressaut avec un nombre de Froude autour de 8-9 permet de maximiser a quantite d'air entrainee.

Mots-cles: ressaut hydrauliques, taux de vide, champs de vitesses, entrainement d'air, selfsimilarite, nombre de Reech-Froude

\section{INTRODUCTION}

Air entrainment takes place spontaneously in open channel flows when the turbulent shear stress next to the air-water interface is large enough to overcome the surface tension (Ervine and Falvey 1987; Chanson 2009). A canonical case is the self-aeration associated with the occurrence of flow singularity, e.g. in a plunging jet or hydraulic jump. The singular selfaerated flow is characterised by intense turbulent mixing and a large rate of energy dissipation, thus widely utilised in industrial processing (chemical mixing, wastewater oxygenation, etc.) and hydraulic structures (Henderson 1966; Hoyt and Sellin 1989). Figure 1 illustrates an application of hydraulic jump as energy dissipator, where the splashing "white water" appearance of the jump can be seen from the aerial view over the dam spillway and stilling basin during a minor flood. Although in most cases the air-water exchange is an uncontrolled process, the aeration rate can be sometimes critical for meeting biochemical oxygen demand, prediction of flow bulking or prevention of cavitation erosion. However, the characterisation of air-water flow properties in hydraulic jumps is not easy (Rajaratnam 1962). While the difficulty of prototype measurement is evident, the major challenges for analytical and numerical simulations are associated with the involvement of numerous two-phase flow parameters and interactive physical processes, as well as the lack of benchmark data for model validation (Chanson 2013). To date, the most constructive information is obtained from physical modelling, though the applicable measuring techniques are far fewer than those broadly used in monophase flows (Boyer et al. 2002). 
Well-established air-water flow measuring techniques included two-phase flow visualisation, bubble imaging velocimetry (BIV) and intrusive phase-detection probe. Imaging of bubbly flow through the transparent sidewall provided the global distribution of void fraction in an observation plane next to the wall (Mossa and Tolve 1998; Leandro et al. 2012). The flow dynamics and velocity field were characterised in weak hydraulic jumps using the bubbles as tracer particles (Rodríguez-Rodrígueza et al. 2011). Such BIV techniques were deemed to be complementary approaches to traditional particle imaging velocimetry (PIV) and acoustic Doppler velocimetry (ADV) that were only functional in weak jumps with very limited air entrainment (e.g. Liu et al. 2004; Lennon and Hill 2006). More detailed information of instantaneous air entrainment was obtained using conductivity or optical-fibre phasedetection probes that measured the air-water flow locally and intrusively (Rajaratnam 1962; Crowe et al. 1998). A series of previous studies successfully quantified the air-water flow properties of prior interest to industrial engineers, including the void fraction, bubble size spectrum and interfacial velocity distribution (Chanson and Brattberg 2000; Murzyn et al. 2005; Chachereau and Chanson 2011; Wang and Chanson 2015). The existing data indicated the significance of Froude number, Reynolds number and inflow turbulence levels affecting the spatial distributions of these air-water flow properties (see the next section). These data sets may enable preliminary calibration and justification of theoretical and numerical models, but are somehow complicated and unsystematic for practical engineering applications. Before the present study, the only reliable way to depict quantitatively the void fraction distribution and air entrainment flux in highly-aerated hydraulic jumps was to conducting physical modelling under designed flow conditions, which was often uneconomical and unpractical. This paper introduces a method combining theoretical and empirical considerations to estimate the spatial void fraction distribution and air entrainment flux based simply on the inflow Froude number. The present method is based upon the self-similarity of void fraction 
and interfacial velocity distributions within the well-defined jump roller length, and involves calibration of bubble diffusion equation and wall jet velocity equation with experimental results obtained for a broad range of flow conditions.

\section{PHYSICAL MODELLING AND EXPERIMENTAL SETUP}

\section{Dimensional analysis}

The physical modelling of singular aerated flow involves relevant parameters including the fluid properties, channel geometry, inflow conditions and local two-phase flow properties (Kobus 1984; Wood 1991). For a hydraulic jump with inflow depth $\mathrm{d}_{1}$ and average approaching velocity $\mathrm{V}_{1}$, a simplified dimensional analysis yields:

$$
\frac{\mathrm{d}}{\mathrm{d}_{1}}, \mathrm{C}, \frac{\mathrm{V}}{\mathrm{V}_{1}}, \frac{\mathrm{v}^{\prime}}{\mathrm{V}_{1}}, \ldots=\mathrm{F}\left(\frac{\mathrm{x}-\mathrm{X}_{\mathrm{t}}}{\mathrm{d}_{1}}, \frac{\mathrm{y}}{\mathrm{d}_{1}}, \frac{\mathrm{z}}{\mathrm{d}_{1}}, \frac{\mathrm{X}_{\mathrm{t}}}{\mathrm{d}_{1}}, \frac{\delta}{\mathrm{d}_{1}}, \frac{\mathrm{V}_{1}}{\sqrt{\mathrm{g} \times \mathrm{d}_{1}}}, \frac{\rho_{\mathrm{w}} \times \mathrm{V}_{1} \times \mathrm{d}_{1}}{\mu_{\mathrm{w}}}, \frac{\mathrm{g} \times \mu_{\mathrm{w}}{ }^{4}}{\rho_{\mathrm{w}} \times \sigma^{3}}, \ldots\right)
$$

where $\mathrm{d}$ is the local depth, $\mathrm{C}$ is the void fraction, $\mathrm{V}$ is the time-averaged velocity and $\mathrm{v}^{\prime}$ the velocity fluctuation, $\mathrm{x}, \mathrm{y}$ and $\mathrm{z}$ are respectively the longitudinal, vertical and transverse coordinates, $\mathrm{X}_{\mathrm{t}}$ is the longitudinal jump toe position, $\delta$ is the inflow boundary layer thickness at the jump toe $\left(\delta / \mathrm{d}_{1}<1\right.$ for partially-developed impinging flow), $\mathrm{g}$ is the gravity acceleration, $\rho_{\mathrm{w}}$ and $\mu_{\mathrm{w}}$ are the water density and dynamic viscosity, and $\sigma$ is the surface tension between air and water. Equation (1) expresses the basic turbulent aerated flow properties at a position $(\mathrm{x}, \mathrm{y}, \mathrm{z})$ as functions of the inflow Froude number $\mathrm{Fr}_{1}$ (6th term on the right-hand side of Eq. (1)), the Reynolds number Re (7th term), and the Morton number Mo (8th term) which is a constant when both air and water are used in model and prototype. For open channel flows, the traditional application of Froude-similitude implies underestimate of the Reynolds number in down-scaled models (Liggett 1994). Thus a true dynamic similarity is unachievable using undistorted models, and the potential scale effects must be properly assessed before extrapolating physical data to prototype conditions. 
When the dynamic similarity cannot be satisfied, self-similarities become a powerful tool to characterise aerated flow field in similar hydraulic structures irrespective of the physical scale (Barenblatt 1996; Wang 1998). The self-similar relationships were observed for some flow properties in hydraulic jumps, which enabled these flow properties to be obtained by similarity transformations under changes of length and time scales. It is specifically addressed in this paper the self-similarities in terms of jump roller surface profile and the spatial distributions of void fraction and longitudinal velocity. These relationships, as well as the resulting air entrainment flux, may be used for design applications at prototype scales.

\section{Experimental setup and instrumentation}

Experimental data were collected in a horizontal open channel with a rectangular crosssection. The channel was $3.2 \mathrm{~m}$ long and $0.5 \mathrm{~m}$ wide, built with smooth HDPE bed and glass side walls. Water was supplied into a head tank then discharged into the experimental section under a rounded gate of the tank, without inducing vena contracta (Fig. 2). The hydraulic jump was generated by controlling a downstream overshoot gate. For a given upstream gate opening $h$, the jump toe was set at the longitudinal position $X_{t}=h / 0.024, X_{t}$ being the longitudinal distance from the upstream gate $(x=0)$ to the toe $\left(x=X_{t}\right)($ Fig. 2). The flow rate was measured with a Venturi meter in the supply pipeline with an accuracy of $\pm 2 \%$. The inflow depth was read using a pointer gauge, for which the uncertainty was determined by the maximum between $0.2 \mathrm{~mm}$ and the free-surface roughness of the impinging flow.

The air-water flow properties were measured using a dual-tip conductivity phase-detection probe. The probe was manufactured at the University of Queensland. It was equipped with two parallel needle sensors that discriminated air and water phases based on the change in electric resistance (Crowe et al. 1998). The diameter of the central electrode of the sensor was $0.25 \mathrm{~mm}$. Each needle sensor recorded the time series of instantaneous void fraction detected 
on the sensor tip. The longitudinal distance between the leading and trailing tips was $\Delta \mathrm{x}=$ $7.12 \mathrm{~mm}$ (Fig. 2B). The two sensors were excited simultaneously with a scanning rate of 20 $\mathrm{kHz}$ for 45 seconds at each measurement location. A correlation between the sensor signals provided the time-averaged interfacial velocity $V_{x}$ when the sensors were aligned against the longitudinal flow direction. The vertical position of the probe was monitored using a magnetic digital scale with error less than $0.2 \mathrm{~mm}$.

A total of eight experimental flows were investigated corresponding to two upstream gate openings $\mathrm{h}=0.02$ and $0.03 \mathrm{~m}$. A constant inflow length $\mathrm{h} / \mathrm{X}_{\mathrm{t}}=0.024$ was applied, characterising partially-developed inflow conditions with $\delta / \mathrm{d}_{1} \sim 0.7$ to 0.8 . Five Froude numbers from 3.8 to 10 were tested for the smaller gate opening, with the Reynolds numbers ranging from $3.5 \times 10^{4}$ to $9.5 \times 10^{4}$. The lower three Froude numbers were reproduced for the larger gate opening, corresponding to $7.0 \times 10^{4}<\mathrm{Re}<1.4 \times 10^{5}$. The flow conditions are specified in Table 1.

\section{SELF-SIMILARITIES IN VOID FRACTION AND INTERFACIAL VELOCITY DISTRIBUTIONS}

\section{Presentation}

Immediately downstream of the depth discontinuity at the jump toe, the water surface elevation increases gradually along the roller until a constant downstream depth $\mathrm{d}_{2}$ is reached. The ratio $\mathrm{d}_{2} / \mathrm{d}_{1}$, known as the conjugate depth ratio, derives from mass and momentum conservation for a frictionless horizontal two-dimensional flow (Bélanger 1841):

[2] $\quad \frac{\mathrm{d}_{2}}{\mathrm{~d}_{1}}=\frac{1}{2} \times\left(\sqrt{1+8 \times \mathrm{Fr}_{1}^{2}}-1\right)$

The length of jump roller $\mathrm{L}_{\mathrm{r}}$ is defined as the longitudinal distance over which the timeaveraged water surface elevation increases monotonically (Fig. 2B). Table 1 summarises the roller length data for the present flow conditions, where the water surface elevation was 
measured non-intrusively using acoustic displacement meters. A re-analysis of the data of Murzyn et al. (2007), Kucukali and Chanson (2008), Murzyn and Chanson (2009) and Wang and Chanson (2015) suggested the dimensionless roller length as a function of the Froude number:

[3] $\frac{\mathrm{L}_{\mathrm{r}}}{\mathrm{d}_{1}}=6 \times\left(\mathrm{Fr}_{1}-1\right)$

for $2<\mathrm{Fr}_{1}<10$

In the present study, the air-water flow properties are presented at relative longitudinal positions $\left(\mathrm{x}-\mathrm{X}_{\mathrm{t}}\right) / \mathrm{L}_{\mathrm{r}}$ within a full roller length $\left(0<\left(\mathrm{x}-\mathrm{X}_{\mathrm{t}}\right) / \mathrm{L}_{\mathrm{r}}<1\right)$, allowing for a discussion of self-similarity in terms of their spatial distributions.

\section{Void fraction}

For partially-developed inflow conditions, the time-averaged void fraction was measured in a series of previous studies (e.g. Chanson and Brattberg 2000; Murzyn et al. 2005; Chachereau and Chanson 2011). These results were reproduced in the present study with favourable consistency. Figure 3 presents a set of experimental data in a vertical cross-section of jump roller and a sketch of the typical void fraction profile. In Figure 3, the elevation of local trough void fraction $\mathrm{Y}_{\mathrm{Cmin}}$ divides the roller into a turbulent shear layer on the bottom and a free-surface region above. The void fraction profile can be approximated by solving the bubble diffusion equation in the turbulent shear layer $\left(\mathrm{y}<\mathrm{Y}_{\mathrm{Cmin}}\right)$ and free-surface region $(\mathrm{y}>$ $\left.\mathrm{Y}_{\mathrm{Cmin}}\right)$ respectively. In the shear layer, the jump toe acts as a point source of bubbles, and bubble diffusion takes place in the vertical direction while the bubbles are advected longitudinally. The void fraction thus follows a quasi-normal distribution (Crane 1956; Chanson 2010): 
$[4 \mathrm{a}]$

$$
C=C_{\max } \times \exp \left(-\frac{1}{4 \times\left(\frac{D_{t}^{(s)}}{V_{1} \times d_{1}}\right)} \times \frac{\left(\frac{y-Y_{C_{\max }}}{d_{1}}\right)^{2}}{\left(\frac{x-X_{t}}{d_{1}}\right)}\right)
$$

$$
\text { for } \mathrm{y}<\mathrm{Y}_{\mathrm{Cmin}}
$$

where $\mathrm{C}_{\max }$ is the local maximum void fraction in the shear layer, $\mathrm{Y}_{\mathrm{Cmax}}$ is the vertical position of $\mathrm{C}_{\max }$, and $\mathrm{D}_{\mathrm{t}}^{(\mathrm{s})}$ is a depth-averaged diffusivity for $0<\mathrm{y}<\mathrm{Y}_{\mathrm{Cmin}}$. The characteristic elevation $\mathrm{Y}_{\mathrm{Cmax}}$ takes implicitly into account the effects of buoyancy and the interaction between vortex shielding and channel bed. In the upper free-surface region, aeration occurs through the roller surface between air and water phases, and the void fraction distribution follows the Gaussian error function (Brattberg et al. 1998; Murzyn et al. 2005):

$$
C=\frac{1}{2} \times\left(1+\operatorname{erf}\left(\frac{\frac{\mathrm{y}-\mathrm{Y}_{50}}{\mathrm{~d}_{1}}}{2 \times \sqrt{\frac{\mathrm{D}_{\mathrm{t}}^{(\mathrm{r})}}{\mathrm{V}_{1} \times \mathrm{d}_{1}}} \times \sqrt{\frac{\mathrm{x}-\mathrm{X}_{\mathrm{t}}}{\mathrm{d}_{1}}}}\right)\right)
$$

$$
\text { for } \mathrm{y}>\mathrm{Y}_{\mathrm{Cmin}}
$$

where $\mathrm{Y}_{50}$ is the elevation for $\mathrm{C}=0.5, \mathrm{D}_{t}{ }^{(\mathrm{r})}$ is the diffusivity in the free-surface region, and the Gaussian error function is defined as

$[4 \mathrm{c}] \quad \operatorname{erf}(\mathrm{u})=\frac{2}{\sqrt{\pi}} \times \int_{0}^{\mathrm{u}} \exp \left(-\mathrm{t}^{2}\right) \times \mathrm{dt}$

It is acknowledged that the bubble transport in the upper roller was more complicated compared to a pure interfacial aeration process, with involvement of bubble recirculation from the underneath shear layer. In spite of this, Equation (4b) agreed well with the experimental data when appropriate value of $\mathrm{D}_{t}^{(\mathrm{r})}$ was selected (Wang and Chanson 2015).

In Equation (4), the void fraction distribution in jump roller is determined by a number of characteristic values including $\mathrm{C}_{\max }, \mathrm{Y}_{\mathrm{Cmax}}, \mathrm{Y}_{50}, \mathrm{D}_{\mathrm{t}}^{(\mathrm{s})}$ and $\mathrm{D}_{\mathrm{t}}^{(\mathrm{r})}$. Figures $4 \mathrm{~A}$ to $4 \mathrm{C}$ plot the longitudinal variations of these parameters for all tested flow conditions. The local maximum void fraction $C_{\max }$ decreased with increasing distance from the toe (Fig. 4A), while its vertical position $Y_{C \max }$ increased (Fig. 4B). The elevation $Y_{50}$ increased from $d_{1}$ to $d_{2}$ over the roller 
length (Fig. 4B), and its longitudinal distribution almost overlapped with the mean roller surface profile measured with acoustic displacement meters (not shown). The dimensionless diffusivity $\mathrm{D}_{\mathrm{t}}^{(\mathrm{s})} /\left(\mathrm{V}_{1} \times \mathrm{d}_{1}\right)$ was typically between 0.02 and 0.1 in the shear flow, increasing towards downstream, whereas $\mathrm{D}_{\mathrm{t}}^{(\mathrm{r})} /\left(\mathrm{V}_{1} \times \mathrm{d}_{1}\right)$ decreased from 0.08 to 0.0001 in the recirculation region (Fig. 4C). All data showed some similar monotonic trends within in the roller length between different flow conditions. Table 2 summarises the best-fit curves for each characteristic parameter as a function of the relative longitudinal position $\left(\mathrm{x}-\mathrm{X}_{\mathrm{t}}\right) / \mathrm{L}_{\mathrm{r}}$, together with the correlation coefficient R. In Figure 4, the present data of $C_{\max }, Y_{C \max }$ and $D_{t}^{(s)}$ are further compared with the data of Murzyn and Chanson (2009) for $5.1<\operatorname{Fr}_{1}<8.3$, Chanson (2010) for $5.1<\operatorname{Fr}_{1}<11.2$ and Chachereau and Chanson (2011) for $3.1<\operatorname{Fr}_{1}<5.1$, for which the roller lengths were estimated using Equation (3).

Replacing the corresponding parameters in Equation (4) with Equations (C-1) to (C-5) in Table 2 and noting that the ratios $\mathrm{d}_{2} / \mathrm{d}_{1}$ and $\mathrm{L}_{\mathrm{r}} / \mathrm{d}_{1}$ are functions of the Froude number (Eqs. (2) and (3)), the time-averaged void fraction profile at a given longitudinal position $\left(x-X_{t}\right) / d_{1}$ can be fully expressed for a given Froude number. Figure 5 illustrates the analytical void fraction distributions for $\mathrm{Fr}_{1}=5.1$ and 8.5, with comparison to the present experimental data. The analytical prediction corresponding to each experimental data profile is highlighted by dot lines. A summary of correlation coefficients for all measured void fraction profiles is provided in Appendix, showing $70 \%$ of void fraction profiles fitted with $\mathrm{R}>0.95$. Some discrepancy was noticed at the local minimum void fraction $\mathrm{C}_{\min }$ close to the jump toe (e.g. at $\left(\mathrm{x}-\mathrm{X}_{\mathrm{t}}\right) / \mathrm{d}_{1}=4.15, \mathrm{y}=\mathrm{Y}_{\mathrm{Cmin}}$ in Fig. 5B). This was the intermediate area between the shear flow and the free-surface recirculating flow, and the void fraction at such locations was also modified by the plunging wave mechanics under the impact of severe flow reversal and spray projection. Nevertheless, the present void fraction prediction should satisfy the accuracy requirement for most engineering applications with $3.8<\mathrm{Fr}_{1}<10$. Note that viscous scale 
effects may take place when the Reynolds number is small (e.g. $\operatorname{Re}<4 \times 10^{4}$ (Chanson and Chachereau 2013)), with significant drop in the maximum void fraction in the shear layer.

\section{Longitudinal interfacial velocity}

The average longitudinal interfacial velocity was measured between the phase-detection probe tips. In high-speed flows, no-slip condition applies thus the interfacial velocity is considered equal to the flow velocity. Rajaratnam (1965) proposed an analogy between the impinging flow into the jump roller and a wall jet, yielding a theoretical expression of monophase flow velocity distribution, which was later modified by Chanson (2010) to take into account the flow reversal next to the free-surface:

$$
\frac{V_{x}}{V_{\max }}=\left(\frac{y}{Y_{V_{\max }}}\right)^{\frac{1}{N}}
$$$$
\text { for } \frac{\mathrm{y}}{\mathrm{Y}_{\mathrm{V}_{\max }}}<1
$$

$$
\frac{\mathrm{V}_{\mathrm{x}}-\mathrm{V}_{\text {recirc }}}{\mathrm{V}_{\max }-\mathrm{V}_{\text {recirc }}}=\exp \left(-\frac{1}{2} \times\left(1.765 \times\left(\frac{\mathrm{y}-\mathrm{Y}_{\mathrm{V}_{\max }}}{\mathrm{Y}_{0.5}}\right)\right)^{2}\right)
$$$$
\text { for } \frac{\mathrm{y}}{\mathrm{Y}_{\mathrm{V}_{\max }}}>1
$$

In Equation (5), $\mathrm{V}_{\max }$ is the maximum velocity in the shear flow, $\mathrm{Y}_{\mathrm{Vmax}}$ is the corresponding elevation characterising the upper edge of the bottom boundary layer, $\mathrm{V}_{\text {recirc }}$ is the depthaveraged recirculation velocity, $\mathrm{Y}_{0.5}$ is the elevation where $\mathrm{V}_{\mathrm{x}}=\left(\mathrm{V}_{\max }-\mathrm{V}_{\text {recirc }}\right) / 2$ and $\mathrm{N}$ is a constant between 6 and 10. A typical velocity profile is illustrated in Figure 6. Note that the negative velocity was not observed over the whole roller length: the relative length of flow reversal to the jump roller is less than unity and decreases with decreasing Froude number.

Equation (5) describes a self-similar velocity distribution in a jump with a marked roller (i.e. $\mathrm{V}_{\text {recirc }}<0$ ). The analytical profile is determined by characteristic values $\mathrm{V}_{\max }, \mathrm{Y}_{\mathrm{V}_{\max }, \mathrm{Y}_{0.5} \text { and }}$ $\mathrm{V}_{\text {recirc }}$ The experimental results of these parameters are presented in Figures 7A to 7C. While the dimensionless values $\mathrm{V}_{\max } / \mathrm{V}_{1}, \mathrm{Y}_{\mathrm{Vmax}} / \mathrm{d}_{1}$ and $\mathrm{Y}_{0.5} / \mathrm{d}_{1}$ showed similar longitudinal distributions among different flow conditions, the relative recirculation velocity $\mathrm{V}_{\text {recirc }} / \mathrm{V}_{1}$ was 
almost irrelevant to the longitudinal position but overall decreased with increasing Froude number. Table 3 summarises the correlation relationships where all parameters can be expressed as functions of the Froude number based upon Equation (3). Note that Equation $(\mathrm{V}-1)$ in Table 3 implied a free-stream inflow velocity about 10\% higher than the crosssectional average velocity: i.e. $\mathrm{V}_{\mathrm{x}}\left(\mathrm{x}=\mathrm{X}_{\mathrm{t}}\right) \approx 1.1 \times \mathrm{V}_{1}$, which is quantitatively consistent with Chanson and Brattberg (2000). Using Equations (V-1) to (V-4), the vertical velocity profile (Eq. (5)) at a given longitudinal position $\left(\mathrm{x}-\mathrm{X}_{\mathrm{t}}\right) / \mathrm{d}_{1}$ can be determined by the Froude number. A comparison between the analytical solution and experimental data is presented in Figure 8 for $\operatorname{Fr}_{1}=7.5$ and 8.5. Here the experimental data in the reversing flow was a combination of two datasets obtained with opposite probe sensor orientations pointing upstream and downstream. Meaningless velocity samples were removed, including those in the transition layer between positive and negative velocity regions due to the fault of signal correlation technique when the instantaneous velocity direction changed frequently. Figure 8 shows a reasonable agreement between the theoretical expression and physical samples (correlation coefficients for all velocity profiles listed in Appendix). The analytical model predicted the velocity field with a satisfactory accuracy, although it did not predict the location of stagnation where flow recirculation vanished (see the last experimental velocity profile in Fig. $8 \mathrm{~A}$ where $\mathrm{V}_{\mathrm{x}}>0$ through the entire cross-section). Wu and Rajaratnam (1996) measured the transitional velocity from the stagnation to fully-developed downstream flow, suggesting a length of transition region being about $2 \times \mathrm{L}_{\mathrm{r}}$.

\section{AIR ENTRAINMENT FLUX}

Based upon the time-averaged void fraction and interfacial velocity distributions, it is possible to quantify the total air entrainment flux in hydraulic jump. The air entrainment flux is important when the dissolved oxygen level or flow bulking is a critical factor to hydraulic 
facility design. In the presence of recirculating flow, the air entrainment flux $\mathrm{q}_{\mathrm{ent}}$ was calculated separately in the positive and negative velocity regions:

[6a] $\quad \mathrm{q}_{\mathrm{ent}}=\left|\mathrm{q}_{\mathrm{ent}}{ }^{(\mathrm{s})}\right|+\left|\mathrm{q}_{\mathrm{ent}}{ }^{(\mathrm{r})}\right|$

with

$$
\mathrm{q}_{\mathrm{ent}}{ }^{(\mathrm{s})}=\int_{\mathrm{y}=0}^{\mathrm{y}\left(\mathrm{v}_{\mathrm{x}}=0\right)} \mathrm{C} \times \mathrm{V}_{\mathrm{x}} \times \mathrm{dy}>0 \quad \text { for } \mathrm{V}_{\mathrm{x}}>0
$$

$$
\mathrm{q}_{\mathrm{ent}}^{(\mathrm{r})}=\int_{\mathrm{y}\left(\mathrm{V}_{\mathrm{x}}=0\right)}^{\mathrm{Y}_{\mathrm{g}_{0}}} \mathrm{C} \times \mathrm{V}_{\mathrm{x}} \times \mathrm{dy}<0
$$$$
\text { for } \mathrm{V}_{\mathrm{x}}<0
$$

where $\mathrm{q}_{\mathrm{ent}}{ }^{(\mathrm{s})}$ and $\mathrm{q}_{\mathrm{ent}}{ }^{(\mathrm{r})}$ denote respectively the entrapped air fluxes in the shear flow $\left(\mathrm{V}_{\mathrm{x}}>0\right.$, $\left.\mathrm{q}_{\mathrm{ent}}{ }^{(\mathrm{s})}>0\right)$ and recirculating flow $\left(\mathrm{V}_{\mathrm{x}}<0, \mathrm{q}_{\mathrm{ent}}{ }^{(\mathrm{r})}<0\right)$, and $\mathrm{Y}_{90}$ is the elevation where $\mathrm{C}=0.9$, considered as the upper boundary of the open homogeneous air-water flow (Cain and Wood 1981). Figure 9 shows a sketch of the air-water exchange in hydraulic jump roller together with the air fluxes in the shear flow and recirculation region.

Figure 10 shows the theoretical air entrainment fluxes developing along the roller length for a range of Froude numbers, where $\mathrm{q}$ is the specific water discharge. The dimensionless fluxes $\mathrm{q}_{\mathrm{ent}}{ }^{(\mathrm{s})} / \mathrm{q}$ and $\mathrm{q}_{\mathrm{ent}}^{(\mathrm{r})} / \mathrm{q}$ are plotted in Figure $10 \mathrm{~A}$, and the total flux magnitude $\mathrm{q}_{\mathrm{ent}} / \mathrm{q}=$ $\left|\mathrm{q}_{\mathrm{ent}}{ }^{(\mathrm{s})} / \mathrm{q}\right|+\left|\mathrm{q}_{\mathrm{ent}}{ }^{(\mathrm{r})} / \mathrm{q}\right|$ is shown in Figure 10B. In the turbulent shear flow, the ratio of air flux to total water discharge $\mathrm{q}_{\mathrm{ent}}{ }^{(\mathrm{s})} / \mathrm{q}$ rapidly reached a maximum between $\left(\mathrm{x}-\mathrm{X}_{\mathrm{t}}\right) / \mathrm{L}_{\mathrm{r}}=0.1$ and 0.15 , and gradually decreased to zero along the roller as the shear layer was de-aerated. The peak value was almost the same for all Froude numbers except for $\mathrm{Fr}_{1}=3.8$, the average being $\left(\mathrm{q}_{\mathrm{ent}}(\mathrm{s}) / \mathrm{q}\right)_{\max }=23.8 \%$. The sharp increase in air flux between $\left(\mathrm{x}-\mathrm{X}_{\mathrm{t}}\right) / \mathrm{L}_{\mathrm{r}}=0$ and 0.1 reflected a secondary aeration of the shear layer following the impingement point. This was supported by recent high-speed camera observations showing that the bubbles advected in the shear layer consisted of both freshly-entrained air pockets at the jump toe and the bubbles reentrained from the upper roller region into the shear layer by the roller recirculating motion. 
In the free-surface recirculation region, the dimensionless air flux $\mathrm{q}_{\mathrm{ent}}{ }^{(\mathrm{r})} / \mathrm{q}$ varied significantly for Froude numbers less than 7.5. A maximum recirculating air flux magnitude was reached at $\left(\mathrm{x}-\mathrm{X}_{\mathrm{t}}\right) / \mathrm{L}_{\mathrm{r}}=0.2$ to 0.35 . This was also the location where maximum roller surface fluctuation magnitude was observed at the free-surface (Wang et al. 2015). Downstream of this position, large-scale free-surface turbulence was gradually dissipated, and the associated interfacial aeration was overcome by the de-aeration process.

A portion of bubbles convected in the shear layer were driven into the free-surface recirculation region by large vortices and buoyancy. The air flux $\mathrm{q}_{\mathrm{ent}}{ }^{(\mathrm{s})}$ thus acted as a source of the recirculating air flux $\mathrm{q}_{\mathrm{ent}}{ }^{(\mathrm{r})}$, and the difference $\left|\mathrm{q}_{\mathrm{ent}}{ }^{(\mathrm{r})}\right|-\left|\mathrm{q}_{\mathrm{ent}}{ }^{(\mathrm{s})}\right|$ may correspond to the airwater exchange through the roller surface. For small Froude numbers, $\left|\mathrm{q}_{\mathrm{ent}}{ }^{(\mathrm{r})}\right|-\left|\mathrm{q}_{\mathrm{ent}}{ }^{(\mathrm{s})}\right|<0$ indicated that only a small percentage of bubbles entrained at the toe were involved in the recirculating motion and the rest were convected downstream and released at the tailwater surface. By contrary, $\left|\mathrm{q}_{\mathrm{ent}}{ }^{(\mathrm{r})}\right|-\left|\mathrm{q}_{\mathrm{ent}}{ }^{(\mathrm{s})}\right|>0$ for larger Froude numbers implied an extra amount of air entrainment through the roller free-surface. These can be seen in Figure 10 for $\mathrm{Fr}_{1}>6.6$. The results suggested a considerable contribution of interfacial air-water exchange to the flow aeration in hydraulic jumps, though the singular aeration at the jump toe may be responsible for the most efficient air-water mixing, because the high shear stresses ensure a large bubble count hence large interfacial area for mass transfer.

For a given Froude number, the maximum total air flux magnitude observed along the roller length, $\left(\mathrm{q}_{\mathrm{ent}}\right)_{\max }=\left(\left|\mathrm{q}_{\mathrm{ent}}{ }^{(\mathrm{s})}\right|+\left|\mathrm{q}_{\mathrm{ent}}{ }^{(\mathrm{r})}\right|\right)_{\max }$, may characterise the largest aeration capacity of the jump. Such maximum air flux magnitude was reached at the longitudinal position $\left(x-X_{t}\right) / L_{r}=$ 0.18 to 0.36 (Fig. 10B), and the dimensionless value was a function of the Froude number (Fig. 11). Figure 11 indicates that a Froude number higher than 6.6 was able to provide a maximum air flux ratio over $50 \%$, and the highest aeration rate was achieved with a Froude number between 8 and 9. In such optimal conditions, the singular air entrainment at the jump 
toe contributed $40-45 \%$ of the total air flux in the roller, the rest being the interfacial aeration through the breaking free-surface. A further increase in Froude number would not improve the aeration level in the shear flow, as can be seen in Figure 10A, and the interfacial aeration through the roller surface would also reach an upper limit.

\section{SCALE EFFECTS FOR FROUDE-SIMILAR MODELLING}

The adoption of Froude-similarity in laboratory-scale hydraulic jump modelling leads to potential scale effects due to the down-scaling of Reynolds number. The affected air-water flow properties include the bubble count rate, bubble size spectrum and bubble clustering behaviours (Chanson and Chachereau 2013). The air entrainment and transport may be also affected because of the close linkage to the turbulence development at the flow discontinuity (jump toe) and in the shear layer. Figure 12 presents a comparison of the local maximum void fraction $\mathrm{C}_{\max }$ for Froude-similar flow conditions. The maximum void fraction in the shear layer is shown to increase with increasing Reynolds number, though an upper limit is believed to exist. The scale effects on the overall air entrainment in the shear flow are deemed to be significant when the Reynolds number drops below $4 \times 10^{4}$ to $6 \times 10^{4}$ (Chanson and Chachereau 2013).

The Reynolds number did not appear in the present analytical model. The model was calibrated using experimental data collected for $3.5 \times 10^{4}<\operatorname{Re}<1.6 \times 10^{5}$, and the limited range of Reynolds number might be responsible to some extent for the data scatter of each parameter in Figure 4, resulting in some bias of the prediction of void fraction hence air entrainment flux in the shear layer. In practice, the favourable agreement between model prediction and experimental results suggested negligible bias associated with the scale effects. This was supported by the shear layer air flux data $\left(\mathrm{q}_{\mathrm{ent}}{ }^{(\mathrm{s})} / \mathrm{q}>0\right)$ shown in Figure 12 , which appeared to be independent of the Reynolds number. Herein the air flux data were directly 
derived from the experimental void fraction and interfacial velocity results measured by the phase-detection probe. A further validation of the present model using prototype data would be valuable for its application under much higher Reynolds numbers.

\section{CONCLUSION}

In a hydraulic jump with partially-developed inflow conditions, the void fraction and velocity distributions can be simply predicted using its inflow Froude number $\mathrm{Fr}_{1}$. This was achieved by selecting the jump roller length $L_{r}$ as a characteristic length scale, over which a number of characteristic air-water flow properties followed self-similar distributions. These characteristic air-water flow properties derived from the theoretical expressions of void fraction and velocity. The dimensionless roller length $\mathrm{L}_{\mathrm{r}} / \mathrm{d}_{1}$, quantified based on free-surface profile measurements, was found to increase linearly with the Froude number. This established a direct connection between the void fraction/velocity profiles and the Froude number. For a given Froude number, the spatial void fraction and velocity distributions were predicted with satisfactory accuracies. The analytical model fitted the majority of present experimental void fraction profiles with correlation coefficients greater than 0.95 . The correlation coefficients were typically above 0.90 in terms of fitting the longitudinal velocity profiles. The model applies to a wide range of Froude numbers from 3.8 to 10 .

The successful simulation of time-averaged void fraction and longitudinal velocity further yielded the air entrainment flux in the jump roller. The total air entrainment flux, which is the sum of the positive air flux in the shear layer and the absolute value of negative air flux in the free-surface recirculation region, reached a spatial maximum at $1 / 5$ to $1 / 3$ roller length downstream of the toe. The maximum total air flux could reach up to $50-60 \%$ of the water discharge for Froude numbers greater than 6.6, and the highest aeration rate was achieved with $\mathrm{Fr}_{1}=8$ to 9 . While the air entrainment ratio from jump toe was similar between different 
Froude numbers, the air flux contribution of free-surface aeration varied substantially, negligible for small Froude numbers but significant for moderate to large Froude numbers.

The analytical model introduced in this paper allows for a simple and accurate prediction of time-averaged void fraction, velocity hence air entrainment flux in hydraulic jump. The model is valuable in hydraulic engineering applications when air entrainment is a basic concern but onsite measurement is unpractical or uneconomical.

\section{ACKNOWLEDGEMENTS}

The authors thank Jason Van Der Gevel and Stewart Matthews (the University of Queensland) for their technical assistance. The post-processing of phase-detection probe signal was facilitated by the software developed by Dr Stefan Felder (University of New South Wales). The research project was supported by the Australian Research Council (Grant DP120100481).

\section{REFERENCES}

Barenblatt, G.I. 1996. Scaling, self-similarity, and intermediate asymptotics. Cambridge University Press, Cambridge.

Bélanger, J.B. 1841. Notes sur l'hydraulique. (Notes on hydraulic engineering.) Ecole Royale des Ponts et Chaussées, Paris, France (in French).

Boyer, C., Duquenne, A.M., and Wild, G. 2002. Measuring techniques in gas-liquid and gasliquid-solid reactors. Chemical Engineering Science. 57(16): 3185-3215.

Brattberg, T., Chanson, H., and Toombes, L. 1998. Experimental investigations of freesurface aeration in the developing flow of two-dimensional water jets. Journal of Fluids Engineering, Transactions ASME. 120(4): 738-744. 
Cain, P., and Wood, I.R. 1981. Measurements of self-aerated flow on spillways. Journal of Hydraulic Division, ASCE. 107(HY11): 1425-1444.

Chachereau, Y., and Chanson, H. 2011. Bubbly flow measurements in hydraulic jumps with small inflow Froude numbers. International Journal of Multiphase Flow. 37(6): 555-564. doi:10.1016/j.ijmultiphaseflow.2011.03.012.

Chanson, H. 2009. Turbulent air-water flows in hydraulic structures: dynamic similarity and scale effects. Environmental Fluid Mechanics. 9: 125-142. doi:10.1007/s10652-008-9078-3.

Chanson, H. 2010. Convective transport of air bubbles in strong hydraulic jumps. International Journal of Multiphase Flow. 36(10): 798-814.

Chanson, H. 2013. Hydraulics of aerated flows: qui pro quo? Journal of Hydraulic Research. 51(3): 223-243. doi:10.1080/00221686.2013.795917.

Chanson, H., and Brattberg, T. 2000. Experimental study of the air-water shear flow in a hydraulic jump. International Journal of Multiphase Flow. 26(4): 583-607.

Chanson, H., and Chachereau, Y. 2013. Scale effects affecting two-phase flow properties in hydraulic jump with small inflow Froude number. Experimental Thermal and Fluid Science. 45: 234-242. doi:10.1016/j.expthermflusci.2012.11.014.

Crank, J. 1956. The mathematics of diffusion. Oxford University Press, London.

Crowe, C., Sommerfield, M., and Tsuji, Y. 1998. Multiphase flows with droplets and particles. CRC Press, Boca Raton.

Ervine, D.A., Falvey, H.T. 1987. Behaviour of turbulent water jets in the atmosphere and in plunge pools. Proceedings of the Institution of Civil Engineers, London Part2. 83: 295-314.

Henderson, F.M. 1966. Open channel flow. MacMillan Company, New York.

Hoyt, J.W., and Sellin, R.H.J. 1989. Hydraulic jump as 'mixing layer'. Journal of Hydraulic Engineering. 40(3): 1607-1614. 
Kobus, H. 1984. Scale effects in modelling hydraulic structures. Proc. International Symposium on Scale Effects in Modelling Hydraulic Structures, IAHR, Esslingen, Germany. Kucukali, S., and Chanson, H. 2008. Turbulence measurements in hydraulic jumps with partially-developed inflow conditions. Experimental Thermal and Fluid Science. 33(1): 41-53. doi:10.1016/j.expthermflusci.2008.06.012.

Leandro, J., Carvalho, R., Chachereau, Y., and Chanson, H. 2012. Estimating void fraction in a hydraulic jump by measurements of pixel intensity. Experiments in Fluids. 52(5): 13071318. doi:10.1007/s00348-011-1257-1.

Lennon, J.M., and Hill, D.F. 2006. Particle image velocity measurements of undular and hydraulic jumps. Journal of Hydraulic Engineering, ASCE. 132(12): 1283-1294.

Liggett, J.A. 1994. Fluid Mechanics. McGraw-Hill, New York.

Liu, M., Rajaratnam, N., and Zhu, D.Z. 2004. Turbulent structure of hydraulic jumps of low Froude numbers. Journal of Hydraulic Engineering, ASCE. 130(6): 511-520.

Mossa, M., and Tolve, U. 1998. Flow visualization in bubbly two-phase hydraulic jump. Journal of Fluids Engineering, ASME. 120(1): 160-165.

Murzyn, F., Mouaze, D., and Chaplin, J.R. 2005. Optical fibre probe measurements of bubbly flow in hydraulic jumps. International Journal of Multiphase Flow. 31(1): 141-154. doi:10.1016/j.ijmultiphaseflow.2004.09.004.

Murzyn, F., Mouaze, D., and Chaplin, J.R. 2007. Air-water interface dynamic and free surface features in hydraulic jumps. Journal of Hydraulic Research, IAHR. 45(5): 679-685. doi:10.1080/00221686.2007.9521804.

Murzyn, F., and Chanson, H. 2009. Experimental investigation of bubbly flow and turbulence in hydraulic jumps. Environmental Fluid Mechanics. 9(2): 143-159. doi:10.1007/s10652-0089077-4. 
Rajaratnam, N. 1962. An experimental study of air entrainment characteristics of the hydraulic jump. Journal of Instruction Engineering India. 42(7): 247-273.

Rajaratnam, N. 1965. The hydraulic jump as a wall jet. Journal of Hydraulics Division, ASCE. 91(HY5): 107-132.

Resch, F.J., and Leutheusser, H.J. 1972. Le ressaut hydraulique: mesure de turbulence dans la région diphasique. (The hydraulic jump: turbulence measurements in the two-phase flow region.) Journal La Houille Blanche. 4: 279-293 (in French).

Rodríguez-Rodrígueza, J., Marugán-Cruzb, C., Alisedac, A., and Lasheras, J.C. 2011. Dynamics of large turbulent structures in a steady breaker. Experimental Thermal and Fluid Science. 35(2): 301-310.

Wang, L. 1998. Self-similarity of fluid flows. Applied Physics Letters. 73(10): 1329-1330.

Wang, H., and Chanson, H. 2015. Experimental study of turbulent fluctuations in hydraulic jumps. Journal of Hydraulic Engineering, ASCE. 141(7): 04015010. doi:10.1061/(ASCE)HY.1943-7900.0001010.

Wang, H., Felder, S., and Chanson, H. 2014a. An experimental study of turbulent two-phase flow in hydraulic jumps and application of a triple decomposition technique. Experiments in Fluids. 55: 1775. doi:10.1007/s00348-014-1775-8.

Wang, H., Murzyn, F., and Chanson, H. 2014b. Total pressure fluctuations and two-phase flow turbulence in hydraulic jumps. Experiments in Fluids. 55: 1847. doi:10.1007/s00348014-1847-9.

Wang, H., Murzyn, F., and Chanson, H. 2015. Interaction between free-surface, two-phase flow and total pressure in hydraulic jump. Experimental Thermal and Fluid Science. 64: 3041. doi:10.1016/j.expthermflusci.2015.02.003.

Wood, I.R. 1991. Air entrainment in free-surface flows. IAHR Hydraulic Structures Design Manual No.4, Hydraulic Design Considerations, Balkema Publ., Rotterdam. 
Wu, S., and Rajaratnam, N. 1996. Transition from hydraulic jump to open channel flow. Journal of Hydraulic Engineering, ASCE. 122(9): 526-528.

\section{LIST OF SYMBOLS}

$\mathrm{C}$

time-averaged void fraction

$\mathrm{C}_{\max }$

local maximum void fraction in shear layer

$\mathrm{D}_{\mathrm{t}}^{(\mathrm{r})}$

recirculating flow diffusivity $\left(\mathrm{m}^{2} / \mathrm{s}\right)$

$\mathrm{D}_{\mathrm{t}}^{(\mathrm{s})}$

shear flow diffusivity $\left(\mathrm{m}^{2} / \mathrm{s}\right)$

$\mathrm{d}_{1}$

inflow depth (m)

$\mathrm{d}_{2}$

conjugate water depth (m)

$\operatorname{Fr}_{1}$

inflow Froude number: $\mathrm{Fr}_{1}=\mathrm{V}_{1} /\left(\mathrm{g} \times \mathrm{d}_{1}\right)^{0.5}$

g

gravity acceleration $\left(\mathrm{m} / \mathrm{s}^{2}\right)$

$\mathrm{h}$

upstream gate opening (m)

$\mathrm{L}$

jump roller length (m)

$\mathrm{q}$

specific water discharge $\left(\mathrm{m}^{2} / \mathrm{s}\right)$

$\mathrm{q}_{\text {ent }}$

air entrainment flux $\left(\mathrm{m}^{2} / \mathrm{s}\right)$

$\mathrm{q}_{\text {ent }}^{(\mathrm{r})}$

negative air entrainment flux in recirculating flow $\left(\mathrm{m}^{2} / \mathrm{s}\right)$

$\mathrm{q}_{\mathrm{ent}}{ }^{(\mathrm{s})}$

positive air entrainment flux in shear flow $\left(\mathrm{m}^{2} / \mathrm{s}\right)$

$\mathrm{Re}$

Reynolds number: $\mathrm{Re}=\rho_{\mathrm{w}} \times \mathrm{V}_{1} \times \mathrm{d}_{1} / \mu_{\mathrm{w}}$

$\mathrm{R}$

normalised correlation coefficient

$\mathrm{V}_{\max }$

maximum longitudinal velocity $(\mathrm{m} / \mathrm{s})$

$\mathrm{V}_{\text {recirc }}$

recirculation velocity $(\mathrm{m} / \mathrm{s})$

$\mathrm{V}_{\mathrm{x}}$

time-averaged longitudinal velocity $(\mathrm{m} / \mathrm{s})$

$\mathrm{V}_{1}$

inflow velocity $(\mathrm{m} / \mathrm{s})$

W

channel width (m) 


$\begin{array}{ll}\mathrm{X}_{\mathrm{t}} & \text { longitudinal jump toe position }(\mathrm{m}) \\ \mathrm{x} & \text { longitudinal distance from upstream gate }(\mathrm{m}) \\ \mathrm{Y}_{\mathrm{Cmax}} & \text { elevation of local maximum void fraction }(\mathrm{m}) \\ \mathrm{Y}_{\mathrm{Cmin}} & \text { elevation of local minimum void fraction }(\mathrm{m}) \\ \mathrm{Y}_{\mathrm{Vmax}} & \text { elevation of maximum longitudinal velocity (m) } \\ \mathrm{Y}_{0.5} & \text { elevation of half maximum longitudinal velocity (m) } \\ \mathrm{Y}_{50} & \text { elevation of void fraction being } 0.5(\mathrm{~m}) \\ \mathrm{Y}_{90} & \text { elevation of void fraction being } 0.9(\mathrm{~m}) \\ \mathrm{y} & \text { vertical distance from channel bed (m) } \\ \mathrm{z} & \text { transverse distance from channel centreline (m) } \\ \Delta \mathrm{x} & \text { longitudinal sensor separation distance (m) } \\ \delta & \text { boundary layer thickness (m) } \\ \mu_{\mathrm{w}} & \text { water viscosity (Pa.s) } \\ \rho_{\mathrm{w}} & \text { water density (m } 3 / \mathrm{s}) \\ \sigma & \text { surface tension between air and water }(\mathrm{N} / \mathrm{m})\end{array}$


$\underline{\text { Tables }}$

Table 1. Flow conditions and jump roller length results

\begin{tabular}{cccccccc|c}
\hline $\begin{array}{c}\mathrm{q} \\
{\left[\mathrm{m}^{2} / \mathrm{s}\right]}\end{array}$ & $\begin{array}{c}\mathrm{W} \\
{[\mathrm{m}]}\end{array}$ & $\begin{array}{c}\mathrm{h} \\
{[\mathrm{m}]}\end{array}$ & $\begin{array}{c}\mathrm{X}_{\mathrm{t}} \\
{[\mathrm{m}]}\end{array}$ & $\begin{array}{c}\mathrm{d}_{1} \\
{[\mathrm{~m}]}\end{array}$ & $\begin{array}{c}\mathrm{V}_{1} \\
{[\mathrm{~m} / \mathrm{s}]}\end{array}$ & $\begin{array}{c}\mathrm{Fr}_{1} \\
{[-]}\end{array}$ & $\begin{array}{c}\mathrm{Re} \\
{[-]}\end{array}$ & $\begin{array}{c}\mathrm{L}_{\mathrm{r}} \\
{[\mathrm{m}]}\end{array}$ \\
\hline 0.0358 & 0.5 & 0.020 & 0.83 & 0.0206 & 1.74 & 3.8 & $3.5 \times 10^{4}$ & 0.28 \\
0.0478 & 0.5 & 0.020 & 0.83 & 0.0209 & 2.29 & 5.1 & $4.8 \times 10^{4}$ & 0.52 \\
0.0694 & 0.5 & 0.020 & 0.83 & 0.0206 & 3.37 & 7.5 & $6.8 \times 10^{4}$ & 0.80 \\
0.0794 & 0.5 & 0.020 & 0.83 & 0.0208 & 3.82 & 8.5 & $8.0 \times 10^{4}$ & 1.00 \\
0.0946 & 0.5 & 0.020 & 0.83 & 0.021 & 4.50 & 10 & $9.5 \times 10^{4}$ & 1.27 \\
\hline 0.0704 & 0.5 & 0.030 & 1.25 & 0.0326 & 2.16 & 3.8 & $7.0 \times 10^{4}$ & 0.60 \\
0.0922 & 0.5 & 0.030 & 1.25 & 0.0322 & 2.86 & 5.1 & $9.2 \times 10^{4}$ & 0.85 \\
0.1418 & 0.5 & 0.030 & 1.25 & 0.033 & 4.30 & 7.5 & $1.4 \times 10^{5}$ & 1.45 \\
\hline
\end{tabular}

Notes: $\mathrm{q}=$ specific flow rate; $\mathrm{W}=$ channel width; $\mathrm{h}=$ upstream gate opening; $\mathrm{X}_{\mathrm{t}}=$ longitudinal jump toe position; $\mathrm{d}_{1}=$ inflow depth upstream of the jump toe; $\mathrm{V}_{1}=$ crosssectional average inflow velocity; $\mathrm{Fr}_{1}=$ inflow Froude number; $\mathrm{Re}=$ Reynolds number; $\mathrm{L}_{\mathrm{r}}=$ length of jump roller 
Table 2. Self-similar longitudinal variations of characteristic void fraction properties required for the determination of time-averaged void fraction distributions

\begin{tabular}{lllc}
\hline Properties & Equation & Best-fit curves & $\mathrm{R}$ \\
\hline $\mathrm{C}_{\max }$ & {$[\mathrm{C}-1]$} & $\mathrm{C}_{\max }=0.5 \times \exp \left(-3.4 \times \frac{\mathrm{x}-\mathrm{X}_{\mathrm{t}}}{\mathrm{L}_{\mathrm{r}}}\right)$ & 0.946 \\
\hline $\mathrm{Y}_{\mathrm{Cmax}}$ & {$[\mathrm{C}-2]$} & $\frac{\mathrm{Y}_{\mathrm{C}_{\max }}-\mathrm{d}_{1}}{\mathrm{~d}_{2}-\mathrm{d}_{1}}=0.56 \times \frac{\mathrm{x}-\mathrm{X}_{\mathrm{t}}}{\mathrm{L}_{\mathrm{r}}}$ & 0.872 \\
\hline $\mathrm{Y}_{50}$ & {$[\mathrm{C}-3]$} & $\frac{\mathrm{Y}_{50}-\mathrm{d}_{1}}{\mathrm{~d}_{2}-\mathrm{d}_{1}}=\left(\frac{\mathrm{x}-\mathrm{X}_{\mathrm{t}}}{\mathrm{L}_{\mathrm{r}}}\right)^{0.536}$ & 0.952 \\
\hline $\mathrm{D}_{\mathrm{t}}^{(\mathrm{s})}$ & {$[\mathrm{C}-4]$} & $\frac{\mathrm{D}_{\mathrm{t}}^{(\mathrm{s})}}{\mathrm{V}_{1} \times \mathrm{d}_{1}}=0.1 \times\left(1-\exp \left(-2.3 \times \frac{\mathrm{x}-\mathrm{X}_{\mathrm{t}}}{\mathrm{L}_{\mathrm{r}}}\right)\right)$ & 0.644 \\
\hline $\mathrm{D}_{\mathrm{t}}^{(\mathrm{r})}$ & {$[\mathrm{C}-5]$} & $\frac{\mathrm{D}_{\mathrm{t}}^{(\mathrm{r})}}{\mathrm{V}_{1} \times \mathrm{d}_{1}}=0.1 \times \exp \left(-3.56 \times \frac{\mathrm{x}-\mathrm{X}_{\mathrm{t}}}{\mathrm{L}_{\mathrm{r}}}\right)$ & 0.938 \\
\hline
\end{tabular}


Table 3. Self-similar longitudinal variations of characteristic interfacial velocity properties required for the determination of time-averaged longitudinal velocity distribution

\begin{tabular}{lllc}
\hline Properties & Equation & Best-fit curves & $\mathrm{R}$ \\
\hline $\mathrm{V}_{\max }$ & {$[\mathrm{V}-1]$} & $\frac{\mathrm{V}_{\max }}{\mathrm{V}_{1}}=1.1 \times \exp \left(-1.2 \times \frac{\mathrm{x}-\mathrm{X}_{\mathrm{t}}}{\mathrm{L}_{\mathrm{r}}}\right)$ & 0.950 \\
\hline $\mathrm{Y}_{\mathrm{V} \max }$ & {$[\mathrm{V}-2]$} & $\frac{\mathrm{Y}_{\mathrm{V}_{\max }}}{\mathrm{d}_{1}}=0.5+0.6 \times \frac{\mathrm{x}-\mathrm{X}_{\mathrm{t}}}{\mathrm{L}_{\mathrm{r}}}$ & 0.704 \\
\hline $\mathrm{Y}_{0.5}$ & {$[\mathrm{~V}-3]$} & $\frac{\mathrm{Y}_{0.5}}{\mathrm{~d}_{1}}=1.8+6 \times \frac{\mathrm{x}-\mathrm{X}_{\mathrm{t}}}{\mathrm{L}_{\mathrm{r}}}$ & 0.951 \\
\hline $\mathrm{V}_{\text {recirc }}$ & {$[\mathrm{V}-4]$} & $\frac{\mathrm{V}_{\text {recirc }}}{\mathrm{V}_{1}}=-0.888+0.273 \times \ln \left(\mathrm{Fr}_{1}\right)$ & 0.876 \\
\hline
\end{tabular}




\section{$\underline{\text { Figure captions }}$}

Fig. 1. Hydraulic jump in the stilling basin at downstream of the Hinze Dam in QLD, Australia; aerial view with flow direction from bottom to top right. The jump was generated by a series of concrete baffles in the stilling basin to enhance energy dissipation and mitigate bank erosion.

Fig. 2. Experimental facility and instrumentation setup

(A) Side view of experimental channel in operation - Flow direction: left to right; flow conditions: $\mathrm{q}=0.694 \mathrm{~m}^{2} / \mathrm{s}, \mathrm{h}=0.02 \mathrm{~m}, \mathrm{X}_{\mathrm{t}}=0.83 \mathrm{~m}, \mathrm{~d}_{1}=0.0206 \mathrm{~m}, \mathrm{Fr}_{1}=7.5, \mathrm{Re}=6.8 \times 10^{4}$

(B) Sketch of experimental channel and phase-detection probe setup

Fig. 3. Vertical distribution of time-averaged void fraction in hydraulic jump roller Experimental results for $\mathrm{Fr}_{1}=7.5, \mathrm{Re}=6.8 \times 10^{4},\left(\mathrm{x}-\mathrm{X}_{\mathrm{t}}\right) / \mathrm{d}_{1}=4.2$ and sketch of typical void fraction profile with key parameters

Fig. 4. Longitudinal variations of characteristic void fraction properties within jump roller length - Comparison with the data of Murzyn and Chanson (2009), Chanson (2009) and Chachereau and Chanson (2011)

(A) Local maximum void fraction in turbulent shear layer

(B) Elevations of local maximum void fraction in shear layer and void fraction being 0.5 next to roller surface

(C) Dimensionless diffusivities in shear layer and free-surface regions

Fig. 5. Analytical solution of void fraction distribution with comparison to experimental data 

(A) $\mathrm{Fr}_{1}=5.1$
(B) $\mathrm{Fr}_{1}=8.5$

Fig. 6. Vertical distribution of time-averaged longitudinal interfacial velocity in hydraulic jump roller - Experimental results for $\mathrm{Fr}_{1}=7.5, \mathrm{Re}=6.8 \times 10^{4},\left(\mathrm{x}-\mathrm{X}_{\mathrm{t}}\right) / \mathrm{d}_{1}=4.2$ and sketch of typical velocity profile with key parameters

Fig. 7. Characteristic interfacial velocity properties within jump roller length

(A) Maximum interfacial velocity in shear flow

(B) Characteristic elevations $\mathrm{Y}_{\mathrm{Vmax}}$ and $\mathrm{Y}_{0.5}$

(C) Depth-averaged recirculation velocity in free-surface region as a function of Froude number - Comparison with data of Chanson (2009) and Chachereau and Chanson (2011)

Fig. 8. Analytical solution of longitudinal velocity distribution with comparison to experimental data
(A) $\mathrm{Fr}_{1}=7.5$
(B) $\mathrm{Fr}_{1}=8.5$

Fig. 9. Sketch of air entrainment and air entrainment flux in hydraulic jump roller

Fig. 10. Longitudinal variation of air entrainment fluxes calculated with theoretical void fraction and velocity distributions
(A) Shear flow air flux (positive) and recirculation air flux (negative)
(B) Total air flux magnitude 
Fig. 11. Ratio of maximum total air flux magnitude to specific water discharge as a function of Froude number

Fig. 12. Effects of Reynolds number on local maximum void fraction and air entrainment flux in turbulent shear layer - experimental data 


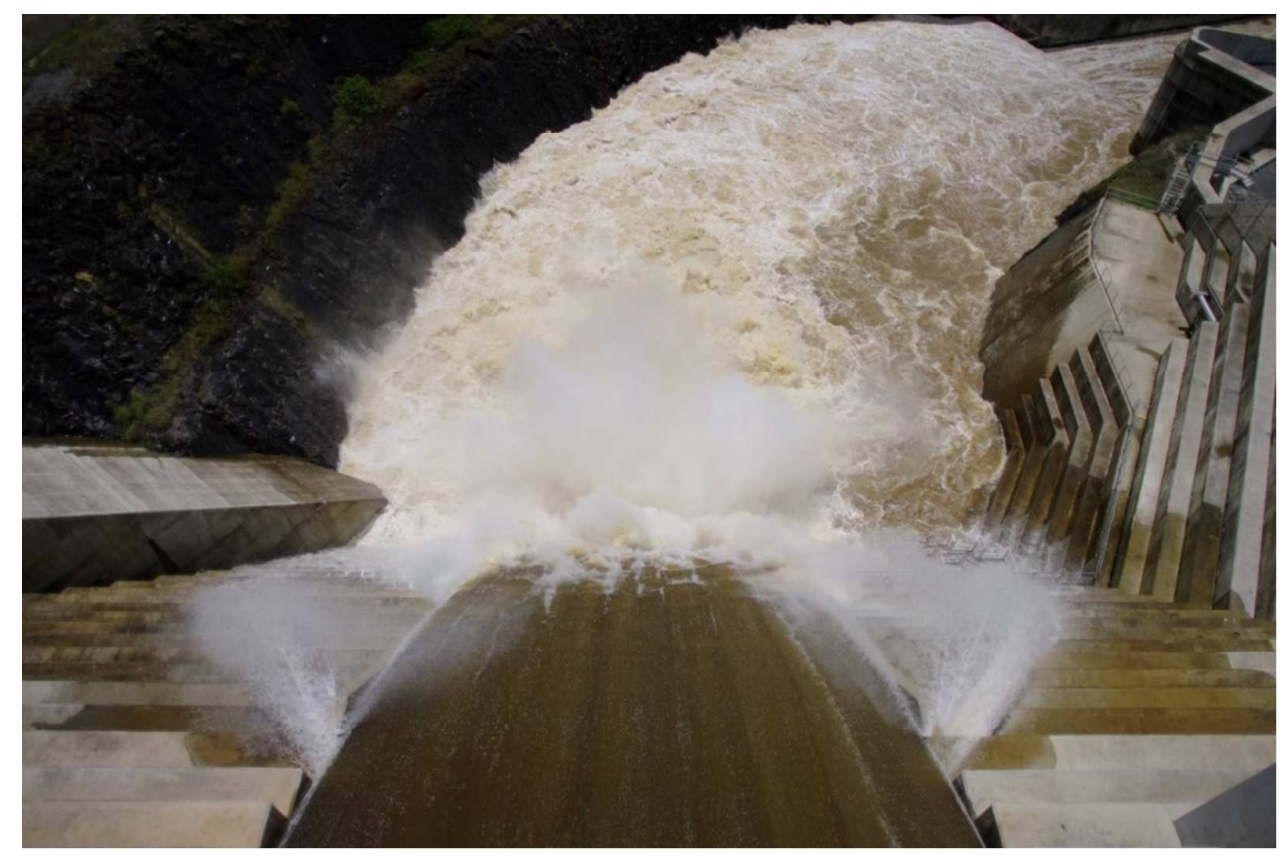


Fig. 2

(a)
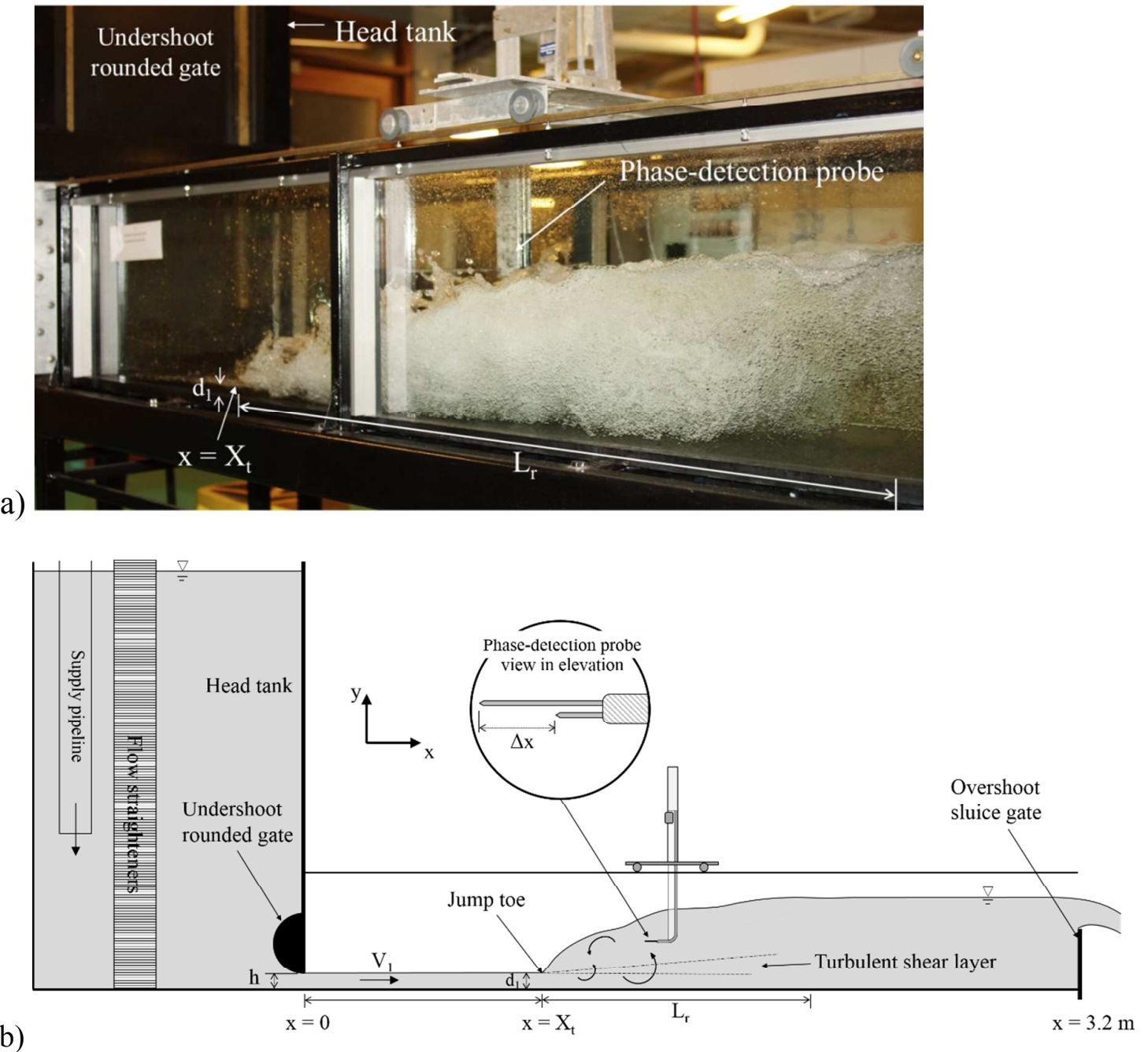

(b) 
Fig. 3

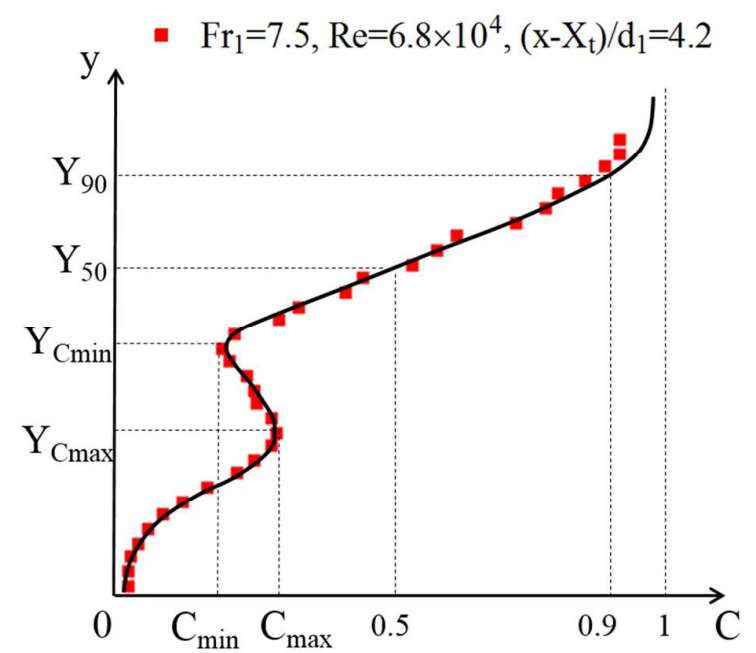


Fig. 4

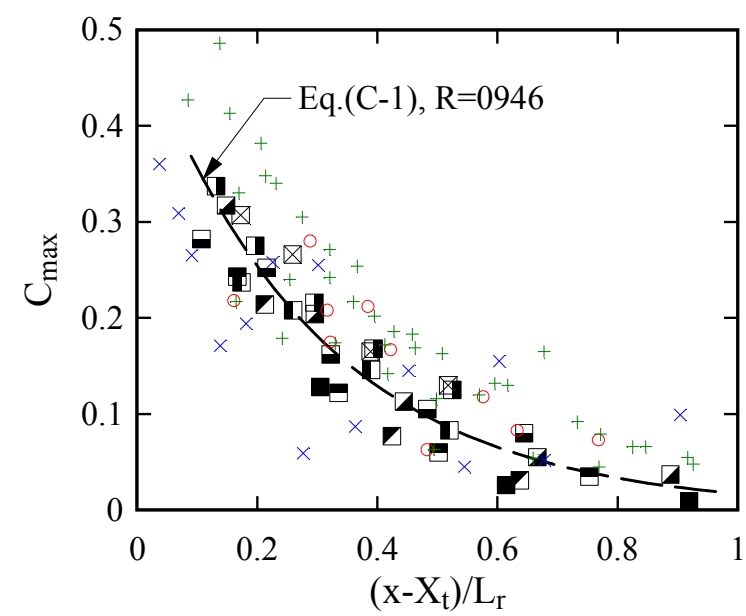

(a)

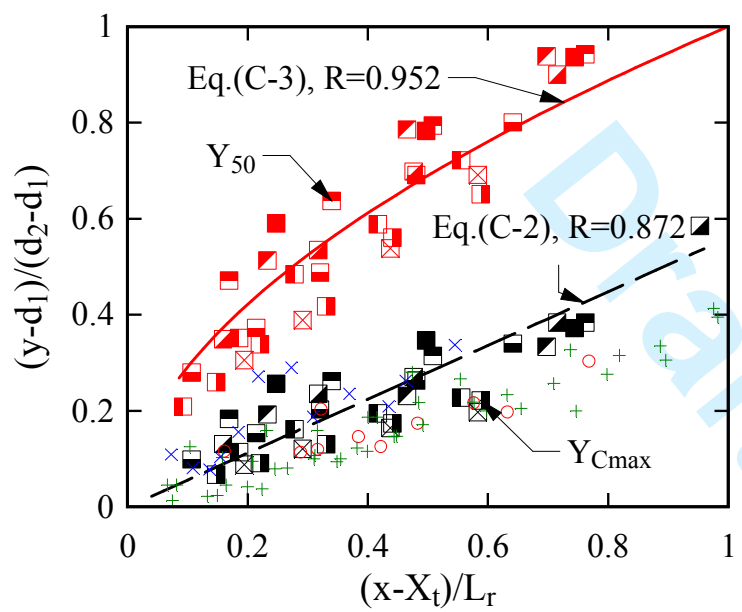

(b)

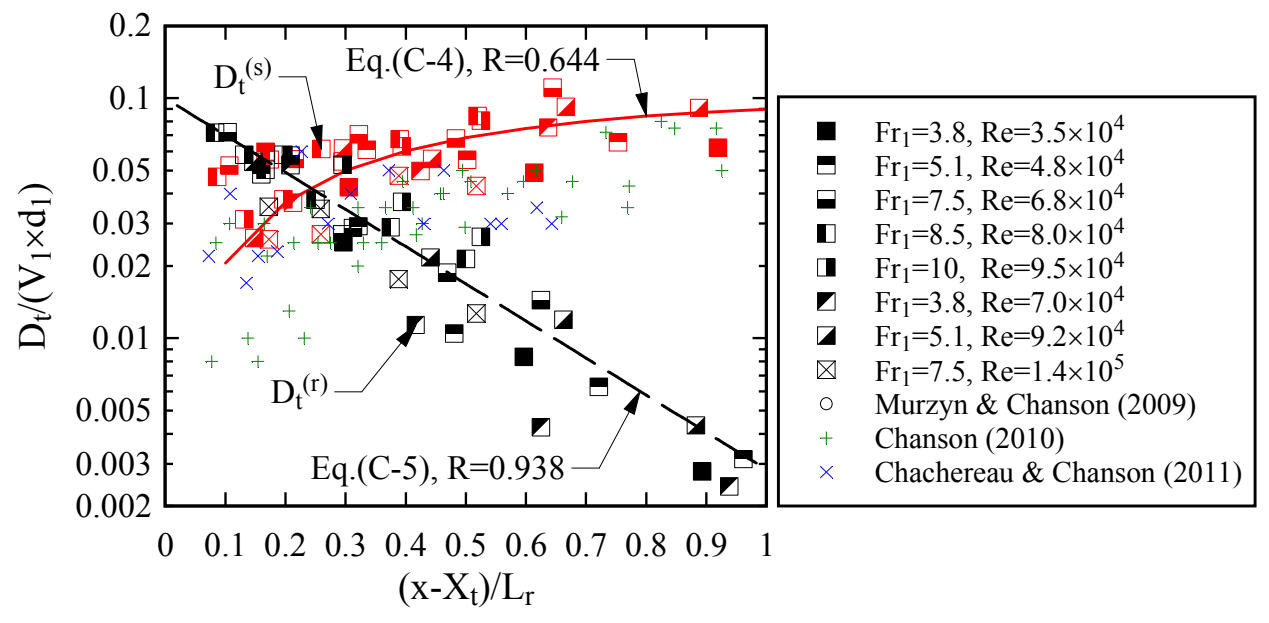


Fig. 5

(a)

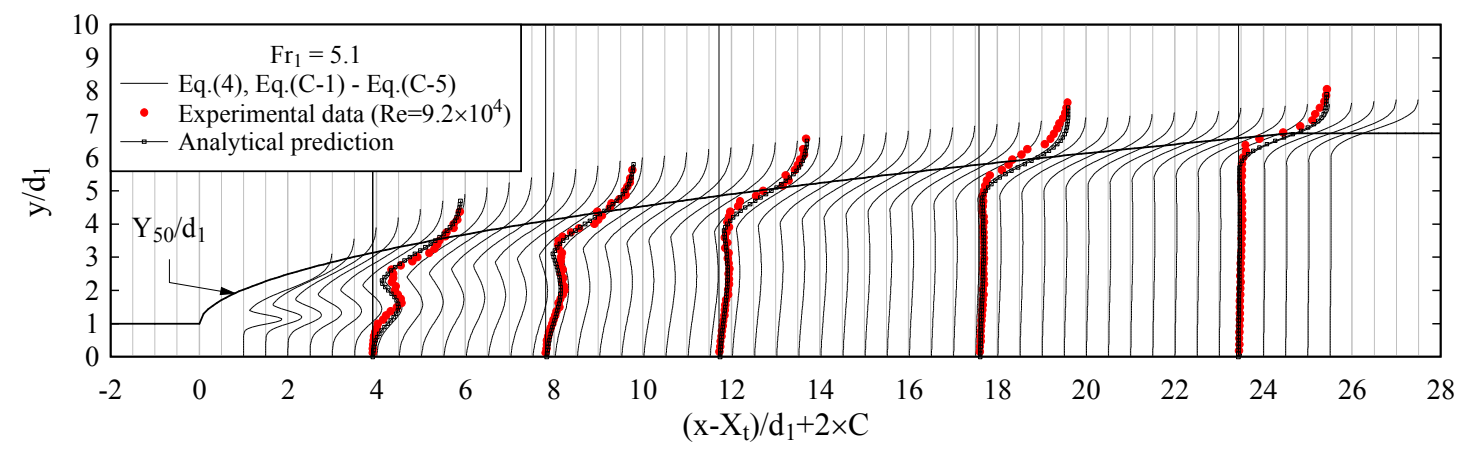

(b)

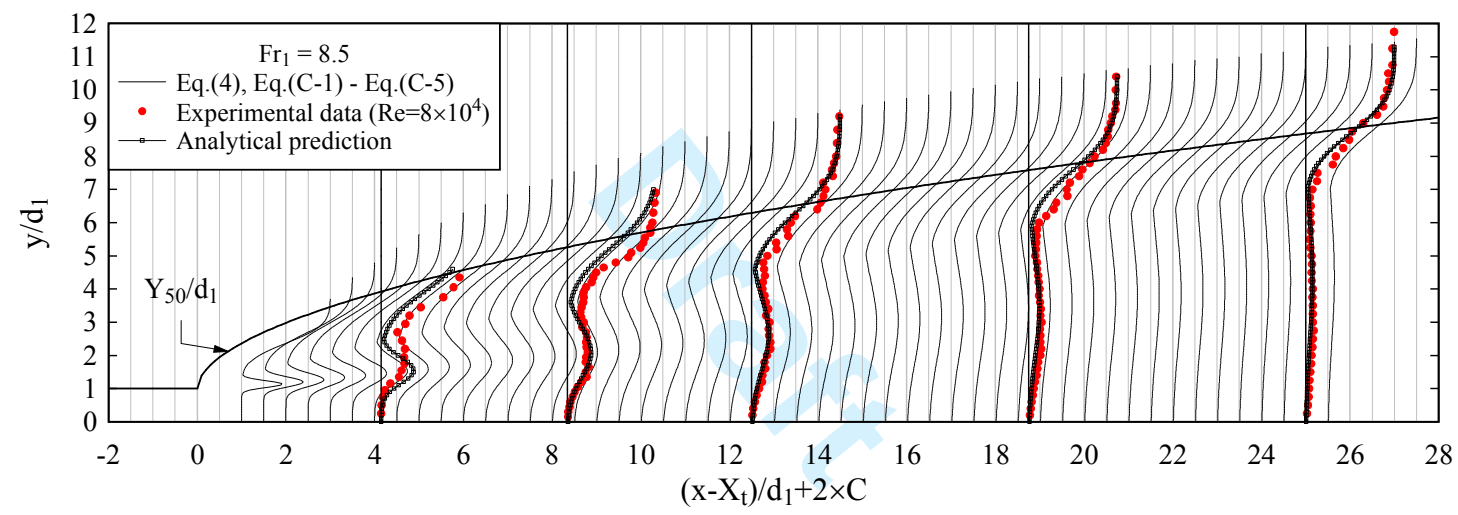


Fig. 6

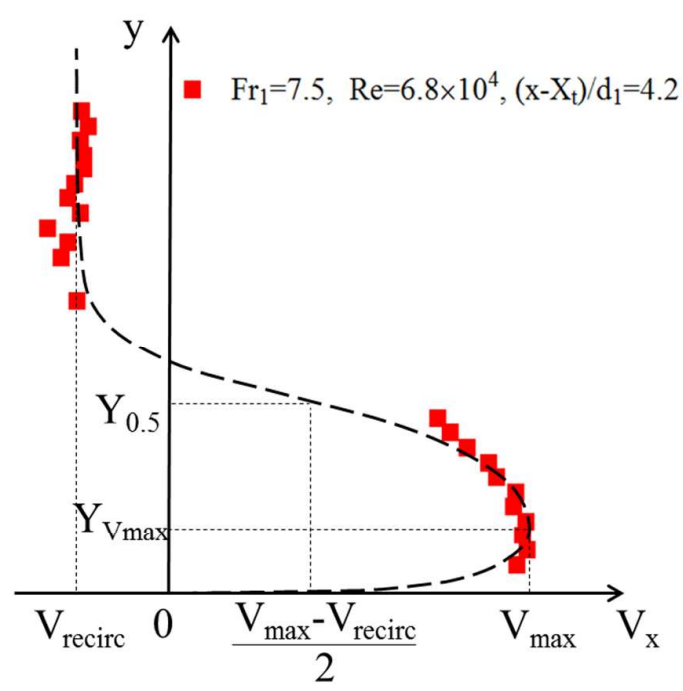


Fig. 7

(a)
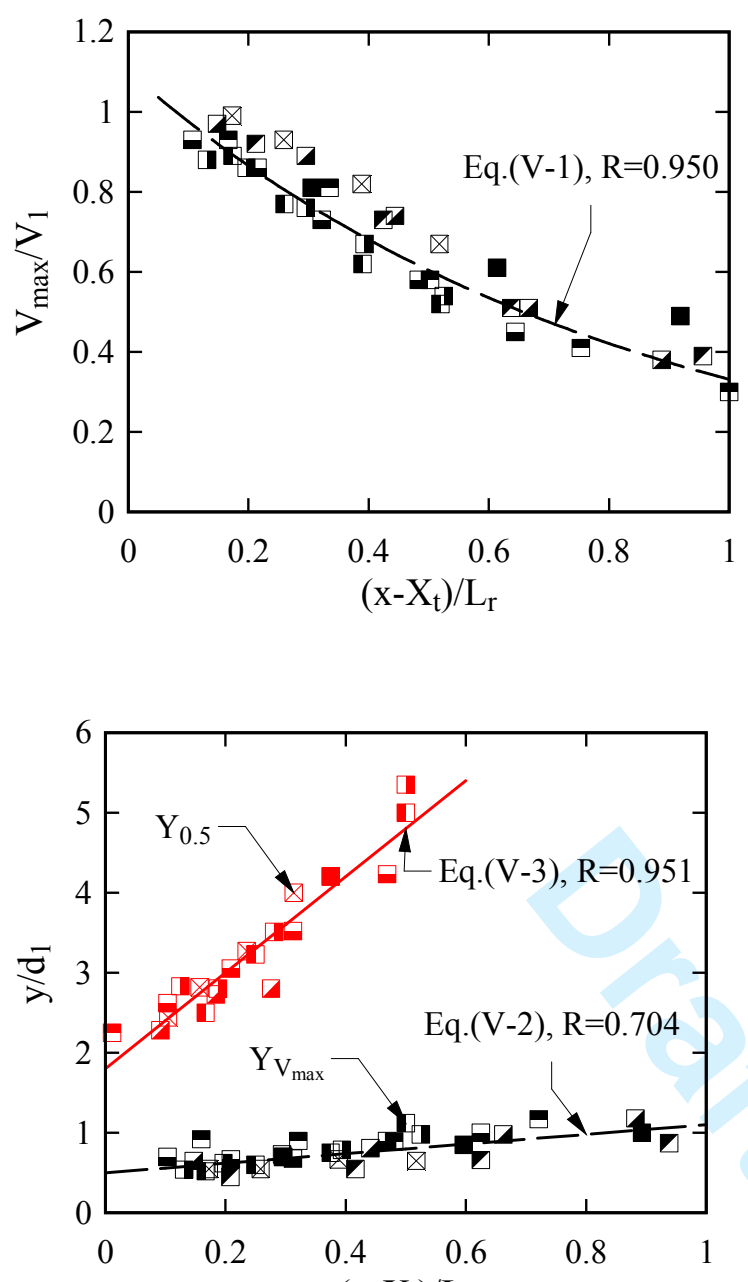

(b)

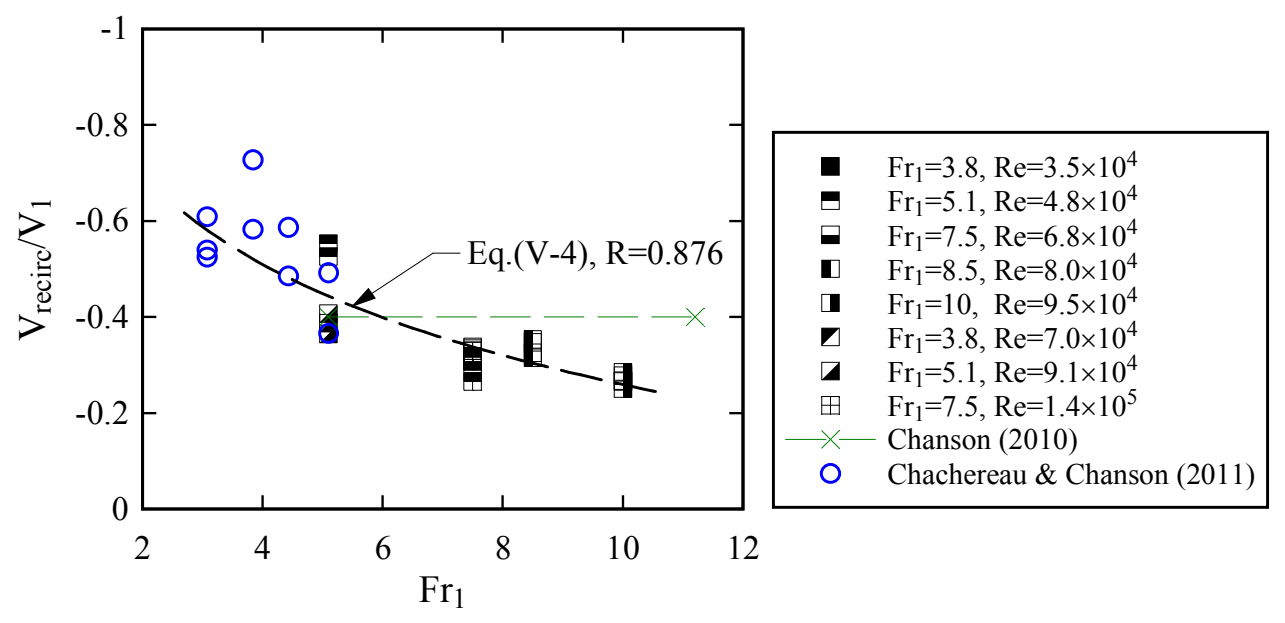

(c) 
Fig. 8

(a)

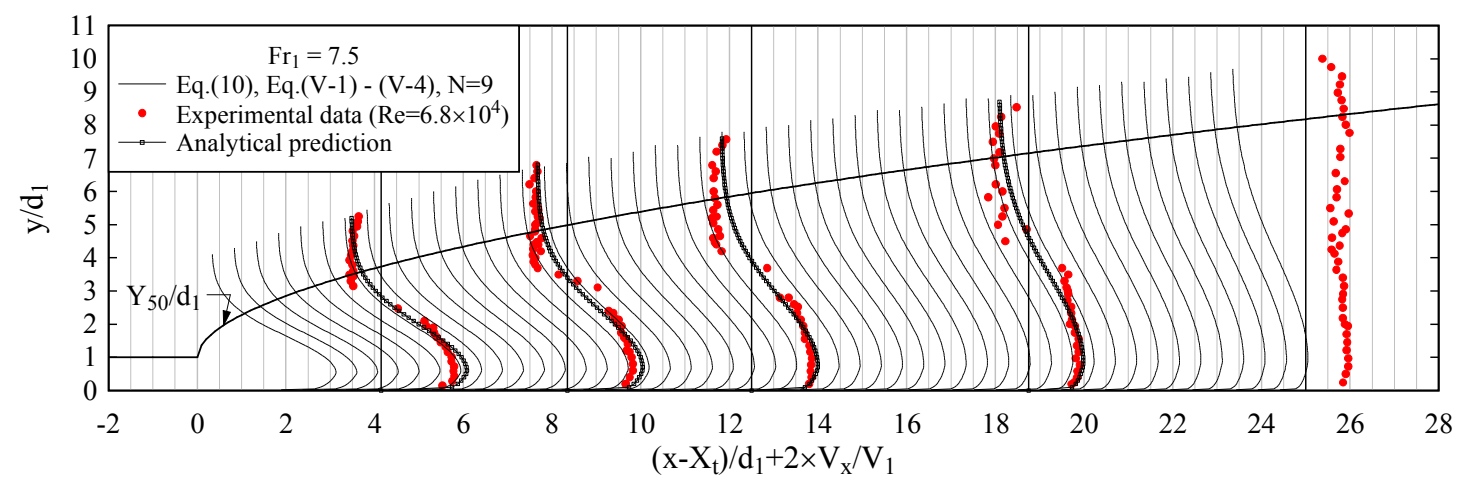

(b)

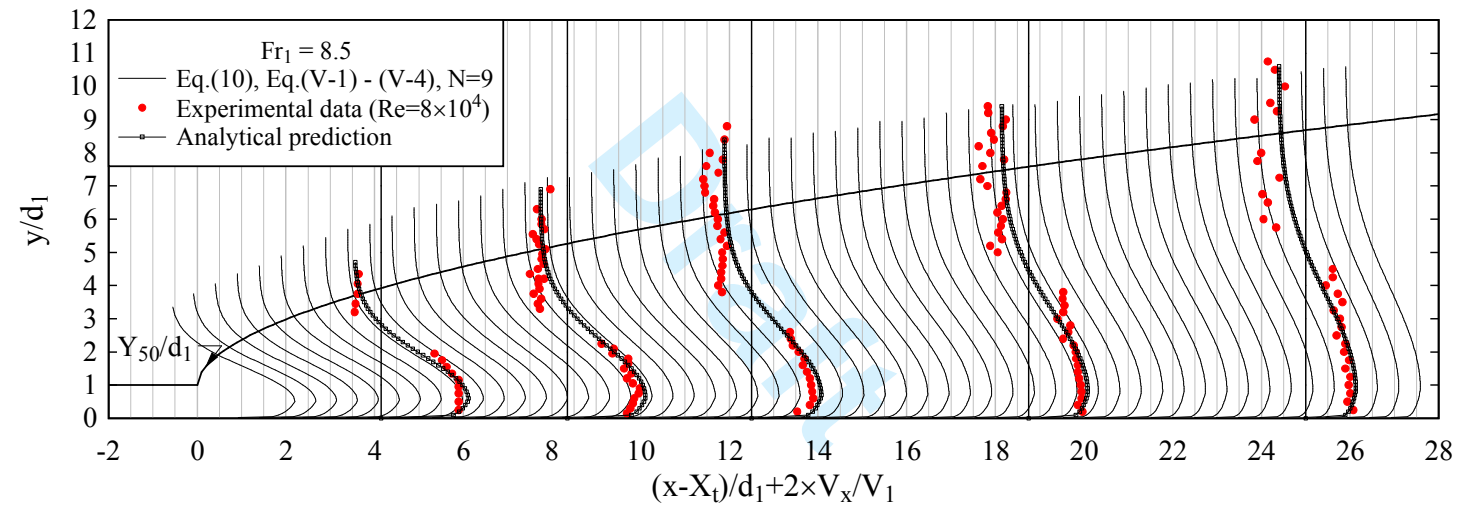


Fig. 9

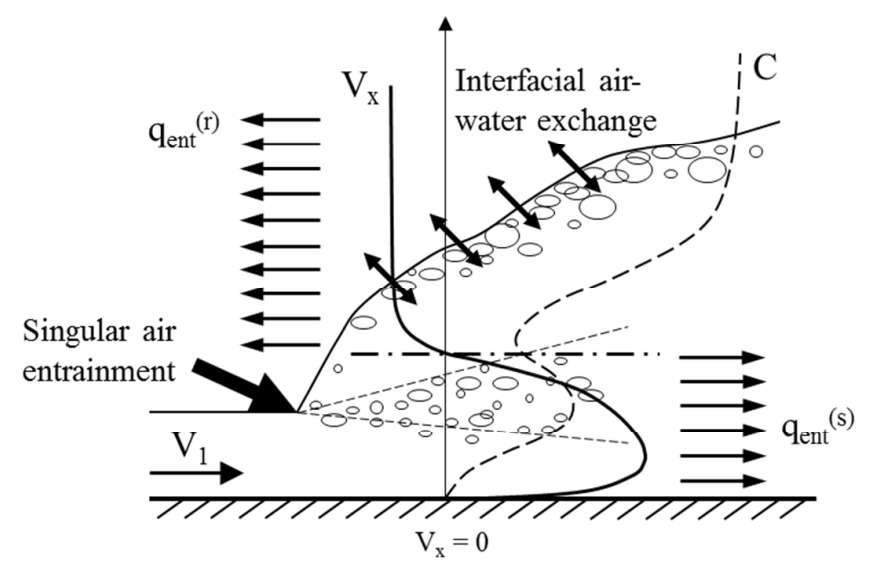


Fig. 10

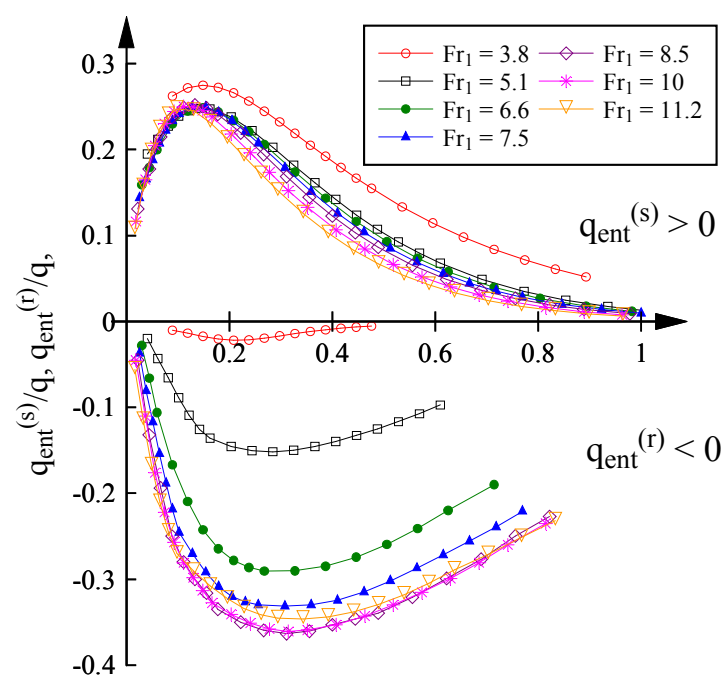

(a)

$$
\left(\mathrm{x}-\mathrm{X}_{\mathrm{t}}\right) / \mathrm{L}_{\mathrm{r}}
$$

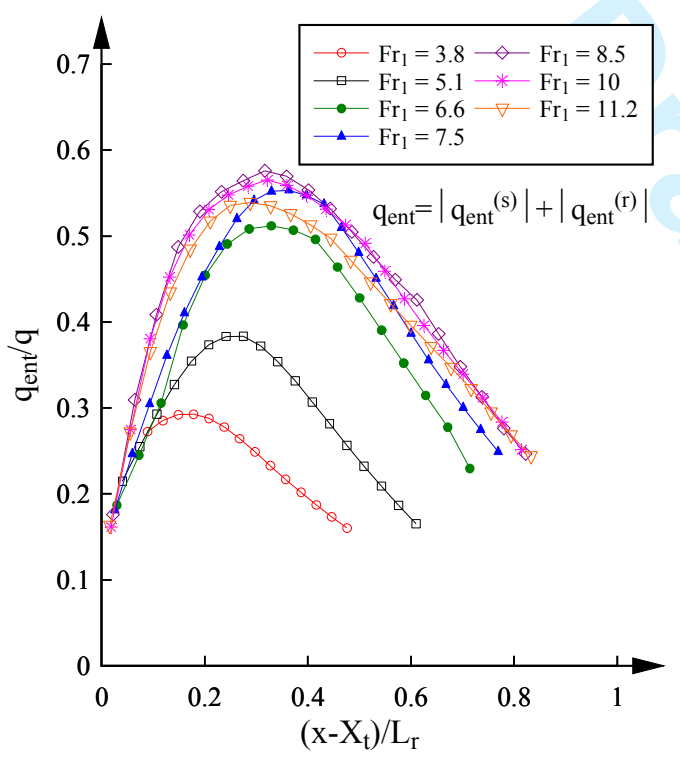

(b) 
Fig. 11

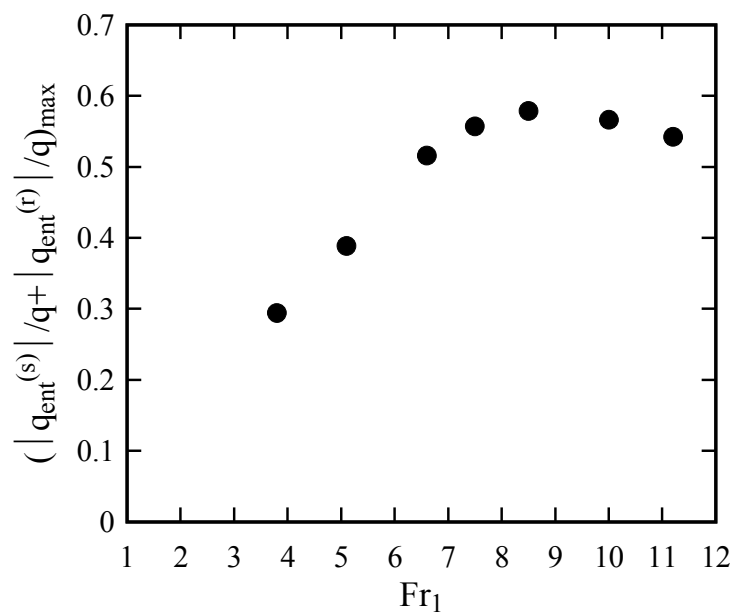


Fig. 12

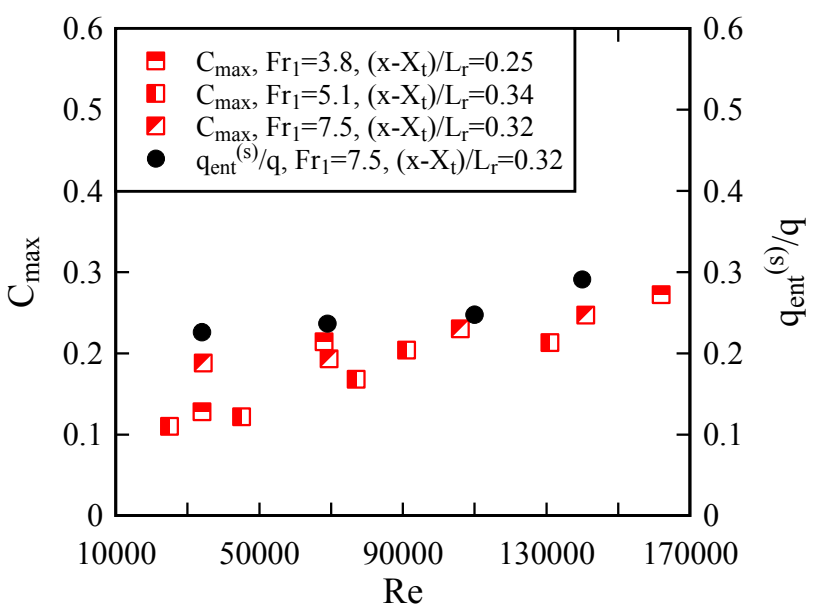




\section{APPENDIX}

The analytical model describing the void fraction distribution for a given Froude number consists of Equations (2) to (4) and (C-1) to (C-5) (Table 2), while the longitudinal velocity model is a combination of Equations (3), (5), (V-1) to (V-4) (Table 3). A measure of the model accuracy is the correlation coefficient between the model prediction and experimental data. Table A-1 summarises the correlation coefficients obtained for all vertical profiles of void fraction (correlation coefficient denoted as $\mathrm{R}(\mathrm{C})$ ) and longitudinal interfacial velocity (correlation coefficient denoted as $\mathrm{R}\left(\mathrm{V}_{\mathrm{x}}\right)$ ) in the present study. Herein $\mathrm{R}\left(\mathrm{V}_{\mathrm{x}}\right)$ was obtained after the removal of physically-meaningless velocity samples, and it was not available at some cross-sections because of the absence of flow reversal in upper roller. The results showed good agreement between the analytical and physical data, hence justified the accuracy of the proposed model. 
Table A-1. Correlation coefficients between experimental data and model prediction in terms of vertical void fraction and longitudinal velocity profiles

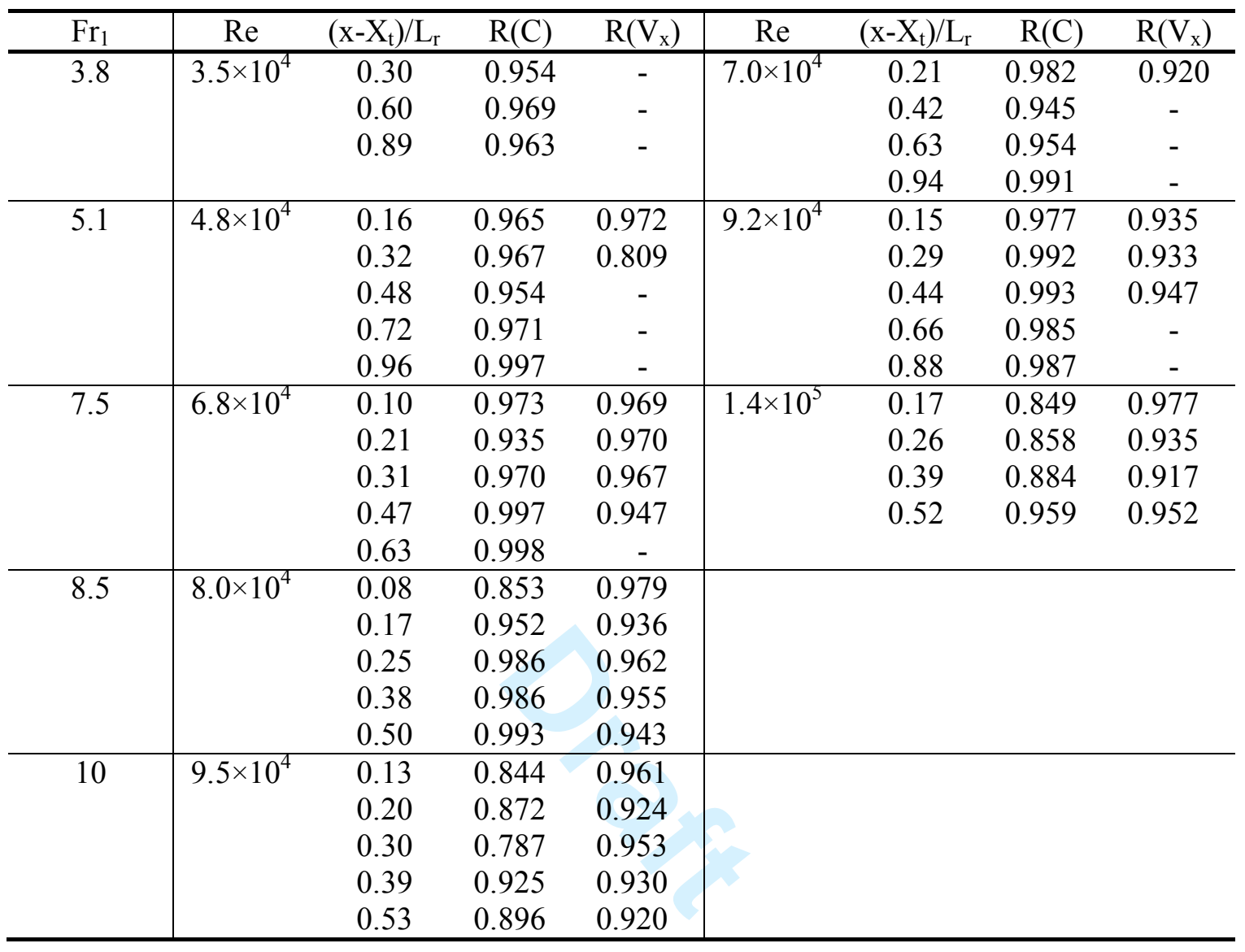

Notes: $\mathrm{R}(\mathrm{C})$ = correlation coefficient between analytical and physical void fraction data; $\mathrm{R}\left(\mathrm{V}_{\mathrm{x}}\right)=$ correlation coefficient between analytical and physical longitudinal velocity data 